\title{
ASSOCIATION OF NFKB1, NKX2-5, GATA4 AND RANKL GENE POLYMORPHISMS WITH SPORADIC CONGENITAL HEART DISEASE IN GREEK PATIENTS
}

\author{
Aidinidou L ${ }^{1}$, Chatzikyriakidou A ${ }^{1}$, Giannopoulos $\mathrm{A}^{2}$, Karpa $\mathrm{V}^{1}$, Tzimou I², Aidinidou E ${ }^{3}$, Fidani L ${ }^{1, *}$ \\ *Corresponding Author: Professor Liana Fidani, Department of General Biology, Medical School, \\ Aristotle University of Thessaloniki, University Campus, GR-54124, Thessaloniki, Greece. Tel.: +30- \\ 231-099-9165. Fax: +30-231-099-9019. E-mail: sfidani@auth.gr
}

\begin{abstract}
Congenital heart disease (CHD) is a group of structural defects of the heart and the great vessels, and one of the leading causes of death among infants and young adults. Several gene variants are involved in diverse mechanisms of cardiac and vessel development and could thus be considered candidate mutated genes for a congenital heart defect or a specific variant could predispose a person to CHD. In the present study, variants in four such genes are investigated for the first time in a group of young Greek CHD patients: the NFKB1 gene polymorphism (-94ins/ delATTG), rs28362491, NKX2-5 gene polymorphism rs2277923, GATA4 gene polymorphism rs11785481 and RANKL gene polymorphism rs4531631. A total of $43 \mathrm{CHD}$ patients and 100 healthy adults were included in the study. The polymerase chain reaction-restriction fragment length polymorphism (PRC-RFLP) method was used to genotype the aforementioned polymorphisms of NFKB1, NKX2-5, GATA4 and RANKL. The association analysis identified that there was a protective association between CHD and the A allele of rs2277923 polymorphism ( $p=0.004)$. The $\mathrm{D}$ allele of the rs 28362491 polymorphism is also a likely risk factor for causing CHD ( $p=0.006)$. The differences of the rs4531631 and rs11785481 variant contribution had no statistical significance between the groups $(p>0.05)$. In conclusion, our results revealed that the rs28362491 and rs2277923 gene polymorphisms, but not the rs4531631

\footnotetext{
${ }^{1}$ Department of Medical Biology-Genetics, Medical School, Aristotle University of Thessaloniki, Thessaloniki, Greece

${ }^{2}$ Second Department of Pediatrics, Pediatric Cardiology Clinic, AHEPA University Hospital, Aristotle University of Thessaloniki, Thessaloniki, Greece

${ }^{3}$ Department of Microbiology, Health Center of Prinos, Thassos Island, Macedonia, Greece
}

and rs11785481 polymorphisms, may contribute to CHD risk in a cohort of Greek CHD patients.

Keywords: Congenital heart disease (CHD); GATA4; NFKB1 (-94ins/delATTG); NKX2-5; RANKL

\section{INTRODUCTION}

Congenital heart disease (CHD), is a structural defect of the heart and the great vessels, and is an important cause of mortality in newborn infants, with an estimated prevalence rate of $1.0 \%$ in live births [1,2]. As a multifactorial disease, both genetics and environmental factors contribute to its development and approximately $30.0 \%$ of CHD present as part of a genetic syndrome or chromosomal abnormality [3]. Multiple environmental factors, such as viral infections with rubella, febrile illness and influenza can affect the fetal development and increase the incidence of CHD. Other implicated maternal factors include diabetes, systemic lupus erythematosus, exposure to therapeutic drugs, alcohol consumption and cigarette smoking $[1,4]$. Nonetheless, to date, the molecular mechanisms that lead to the occurrence of CHD are largely unknown. Up to the present, more than 40 genes encoding transcription factors, signal transduction and structural proteins, have been revealed to be involved in congenital heart defects. Any mutation in these genes may lead to abnormal heart structure and CHD [5,6]. The NKX2-5 and GATA4 genes have been associated with CHD discovered by linkage analysis and candidate gene studies in highly affected families [6].

The NKX2-5 is a member of the NKX2 family located on chromosome 5134 and consists of two exons that encode a 324-amino acid transcription factor. The genetic polymorphism rs2277923 is a synonymous mutation $63 \mathrm{~A}>\mathrm{G}$ leading to an amino acid substitution of glutamine by glutamine at position 21 (Glu21Glu) and was reported as a genetic predictor of CHD [7]. In ad- 
dition, GATA4 interacts with $N K X 2-5$, and it is known that mutations in transcription factors can result in severe cardiac defects [3]. For these reasons, the GATA4 gene polymorphism, an important transcription factor that is involved in the morphogenesis of the heart, was chosen to be studied in order to further validate its pivotal role in modulating CHD risk. Transcription factor GATA4 is a 442-amino acid protein, which is mapped to chromosome 8q22-23 [6]. Consistent with these findings, a common variant $+1158 \mathrm{C}>\mathrm{T}$ (rs11785481) in the 3 ' untranslated region (3'UTR) of the GATA4 gene, was confirmed to be associated with CHD susceptibility, possibly by altering microRNA (miRNA) posttranscriptional regulation [8]. Another transcription factor implicated in the pathogenesis of CHD is the $N F-\kappa B 1$ (nuclear factor- $\kappa \mathrm{B} 1$ ) gene. The $N F-\kappa B$ gene is a member of transcription factors that regulate numerous biological processes such as inflammation, proliferation and cell survival. The $N F-\kappa B$ family has five subunits: p65(RelA), RelB(RelB), c-Rel(Rel), p50/p105 (NFKB1) and p52/p100 (NFKB2) [9].

The human NFKB1 gene is located on chromosome $4 \mathrm{q} 24$ and encodes a $50 \mathrm{kDa}$ DNA-binding peptide (p50). Interestingly, a common -94ins/delATTG variant (rs28362491) that is located on the promoter of the NFKB1 gene, was identified as a potential risk factor for CHD in a Chinese population [9]. A RANKL gene variant was also chosen to be investigated as it has been found that down-regulation of $R A N K L$ may inhibit the $N F-\kappa B$ signaling pathway and lead to a congenital heart anomaly [10]. Receptor activator of the NF- $\kappa \mathrm{B}$ ligand $(R A N K L)$ interacts with $R A N K$ and active $N F-\kappa B$ transcription factor [11]. In line with $N F K B 1$, the genetic variant (rs4531631) in $R A N K L$ might be a significant predisposing factor of CHD [10]. Receptor activator of the NF- $\kappa \mathrm{B}$ ligand $(R A N K L)$, is a 314-amino acid transmembrane protein, encoded by the gene $R A N K$, which is located on chromosome $13 \mathrm{q} 14.11$. The RANKL gene belongs to the TNF cytokine family [12] and expressed by osteoblasts, fibroblasts, and activated $\mathrm{T}$ and B cells. Also, RANKL and RANK also had a combined role on target cells to regulate cell differentiation, activa- tion and apoptosis [13]. Taking these considerations into account, the purpose of the present study was to examine the potential role of these variants in the development of CHD, for the first time, among the Greek population.

\section{MATERIALS AND METHODS}

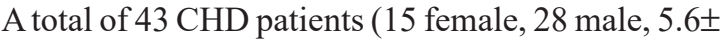
1.6 average age of years), selected based on echocardiogram evidence of CHD and 100 healthy controls with no history of CHD were included in the present study. Genomic DNA of each individual was extracted from a sample of venous blood by use of modified salting out method. The PCR-RFLP method was performed to genotype the polymorphism of NFKB1 (-94ins/delATTG), NKX2-5, GATA4 and RANKL. The primers were designed using the primer-BLAST program in NCBI (National Center for Biotechnology Information) This tool is publicly available at http://www.ncbi.nlm.nih.gov/tools/primer-blast. A New England Biolabs (NEB)-cutter, version 2.0, is a program available via a web server (http://tools.neb. com/ NEB-cutter), was used to find the restriction enzymes. The primer sequences are shown in Table 1.

The amplified $281 \mathrm{bp}$ (deletion allele) or $285 \mathrm{bp}$ (insertion allele) fragments were then digested using PfIMI restriction endonuclease for the $-94 \mathrm{ins} /$ delATTG polymorphism of NFKB1. The wild type allele D yields a 281 bp band and allele I yielded two fragments of 240 and 45 bp, respectively. The A and $\mathrm{G}$ alleles of the $N K X 2-5$ gene polymorphism produced DNA fragments of $264+37$ and $213+51+37$ bp, respectively, using BpmI restriction endonuclease. For the GATA4 gene polymorphism, the $\mathrm{C}$ and $\mathrm{T}$ alleles produced DNA fragments of 261 and $174+87$ $\mathrm{bp}$, respectively, using the $\mathrm{HpyCH} 4 \mathrm{III}$ restriction endonuclease. For the RANKL gene polymorphism, the A and $\mathrm{G}$ alleles produced DNA fragments of $149+61$ and $210 \mathrm{bp}$, respectively, using the EcoRV restriction endonuclease.

All four single nucleotide polymorphisms (SNPs) were assessed for Hardy-Weinberg equilibrium (HWE) by the $\chi^{2}$ test. Statistical analysis was performed by the

Table 1. Primer sequences of NFKB1 rs28362491, NKX2-5 rs2277923, GATA4 rs11785481 and RANKL rs4531631 gene polymorphisms.

\begin{tabular}{|l|l|l|l|l|}
\hline Locus & Primer Sequences $\left(\mathbf{5}^{\prime}>\mathbf{3}^{\prime}\right)$ & $\begin{array}{l}\text { Products } \\
(\mathbf{b p})\end{array}$ & $\begin{array}{l}\text { Annealing } \\
\mathbf{T m}\left({ }^{\circ} \mathbf{C}\right)\end{array}$ & Endonuclease \\
\hline rs28362491 & $\begin{array}{l}\text { F: TGG GCA CAA GTC GTT TAT GA } \\
\text { R: CTG GAG CCG GTA GGG AAG }\end{array}$ & $\begin{array}{l}281 \\
285\end{array}$ & 62 & PfIMI \\
\hline rs2277923 & $\begin{array}{l}\text { F: CTG CCC GGA CAC ATC CAG } \\
\text { R: GTA GGC CTC TGG CTT GAA GG }\end{array}$ & 301 & 62 & BpmI \\
\hline rs11785481 & $\begin{array}{l}\text { F: CTC CTC CTA GCC CTT GGT CA } \\
\text { R: ATC AGG GGC AGA AAC AGC AA }\end{array}$ & 261 & 60 & HypCH4III \\
\hline rs4531631 & $\begin{array}{l}\text { F: CTG GAA GGC TGG CAG TAC TTT } \\
\text { R: TTC CTG CAC ATA GTA GGC TCT T }\end{array}$ & 210 & 62 & ECoRV \\
\hline
\end{tabular}

Tm: melting temperature. 
BALKAN JOURNAL OF MEDICAL GENETICS

Aidinidou L, Chatzikyriakidou A, Giannopoulos A, Karpa V, Tzimou I, Aidinidou E, Fidani L

Table 2. Model of analysis of NFKB1 rs28362491, NKX2-5 rs2277923, GATA4 rs11785481 and RANKL rs4531631 gene polymorphisms in patients with congenital heart disease and control subjects.

\begin{tabular}{|c|c|c|c|c|c|c|c|c|}
\hline \multirow{2}{*}{\begin{tabular}{|l|} 
Locus \\
rs4531631 \\
Reference $^{\mathrm{b}}: \mathrm{G}$ \\
Variant $^{\mathrm{c}}$ :
\end{tabular}} & \multirow{2}{*}{\begin{tabular}{|l|}
$\begin{array}{l}\text { Model of } \\
\text { Analysis }\end{array}$ \\
risk per allele: \\
$0 ; 1 ; 2$
\end{tabular}} & \multicolumn{2}{|c|}{ Cases $(n=43)$} & \multicolumn{2}{|c|}{ Controls $(n=100)$} & \multirow{2}{*}{\begin{tabular}{|l} 
OR $(\mathbf{9 5} \% \mathrm{CI})$ \\
$0.61(0.28-1.32)$
\end{tabular}} & \multirow{2}{*}{$\begin{array}{l}\boldsymbol{p} \text { Value } \\
0.208\end{array}$} & \multirow{2}{*}{$\begin{array}{l}\begin{array}{l}\text { Corrected } \\
p \text { Value }^{\mathrm{a}}\end{array} \\
0.554\end{array}$} \\
\hline & & $\begin{array}{l}\text { RR (\%) } \\
\text { RV (\%) } \\
\text { VV (\%) }\end{array}$ & \begin{tabular}{|c|}
$33(77.0)$ \\
$10(23.0)$ \\
$0(0.0)$
\end{tabular} & \begin{tabular}{|l|} 
RR (\%) \\
RV (\%) \\
VV (\%)
\end{tabular} & $\begin{array}{c}68(68.0) \\
29(29.0) \\
3(3.0)\end{array}$ & & & \\
\hline & VV vs. RR & $\begin{array}{l}\mathrm{RR} \\
\mathrm{VV}\end{array}$ & $\begin{array}{r}33 \\
0\end{array}$ & $\begin{array}{l}\mathrm{RR} \\
\mathrm{VV}\end{array}$ & $\begin{array}{r}68 \\
3\end{array}$ & $0.29(0.02-5.82)$ & 0.550 & 0.554 \\
\hline & RV vs. RR & $\begin{array}{l}\mathrm{RR} \\
\mathrm{RV}\end{array}$ & $\begin{array}{l}33 \\
10\end{array}$ & $\begin{array}{l}\mathrm{RR} \\
\mathrm{RV}\end{array}$ & $\begin{array}{l}68 \\
29\end{array}$ & $0.71(0.31-1.63)$ & 0.419 & 0.554 \\
\hline & $\mathrm{RV}+\mathrm{VV} v s . \mathrm{RR}$ & \begin{tabular}{|l|}
$R R$ \\
$R V+V V$ \\
\end{tabular} & $\begin{array}{l}33 \\
10 \\
\end{array}$ & \begin{tabular}{|l}
$R R$ \\
$R V+V V$
\end{tabular} & $\begin{array}{l}68 \\
32 \\
\end{array}$ & $0.64(0.28-1.47)$ & 0.292 & 0.554 \\
\hline & VV vs. RV+RR & $\begin{array}{l}\text { RR+RV } \\
\text { VV }\end{array}$ & $\begin{array}{r}43 \\
0\end{array}$ & $\begin{array}{l}\text { RR+RV } \\
\mathrm{VV}\end{array}$ & $\begin{array}{r}97 \\
3\end{array}$ & $0.32(0.02-1.47)$ & 0.554 & 0.554 \\
\hline & V vs. R & $\begin{array}{l}\mathrm{R}(\%) \\
\mathrm{V}(\%)\end{array}$ & \begin{tabular}{|l}
$76(88.0)$ \\
$10(12.0)$
\end{tabular} & $\begin{array}{l}\mathrm{R}(\%) \\
\mathrm{V}(\%)\end{array}$ & $\begin{array}{r}165(82.5) \\
35(17.5)\end{array}$ & $0.62(0.29-1.32)$ & 0.211 & 0.554 \\
\hline \multirow[t]{6}{*}{$\begin{array}{l}\text { rs2277923 } \\
\text { Reference }^{\mathrm{b}}: \mathrm{G} \\
\text { Variant }^{\mathrm{c}}: \mathrm{A}\end{array}$} & $\begin{array}{l}\text { risk per allele: } \\
0 ; 1 ; 2\end{array}$ & $\begin{array}{l}\text { RR (\%) } \\
\text { RV (\%) } \\
\text { VV (\%) }\end{array}$ & $\begin{array}{r}7(16.0) \\
26(61.0) \\
10(23.0)\end{array}$ & \begin{tabular}{|l} 
RR (\%) \\
RV (\%) \\
VV (\%)
\end{tabular} & $\begin{array}{c}7(7.0) \\
44(44.0) \\
49(49.0)\end{array}$ & $0.42(0.24-0.76)$ & 0.004 & 0.008 \\
\hline & VV vs. RR & $\begin{array}{l}\text { RR } \\
\text { VV }\end{array}$ & $\begin{array}{r}7 \\
10\end{array}$ & $\begin{array}{l}\text { RR } \\
\text { VV }\end{array}$ & $\begin{array}{r}7 \\
49\end{array}$ & $0.20(0.06-0.71)$ & 0.015 & 0.023 \\
\hline & RV vs. RR & $\begin{array}{ll}\mathrm{RR} \\
\mathrm{RV}\end{array}$ & $\begin{array}{r}7 \\
26 \\
\end{array}$ & $\begin{array}{l}\mathrm{RR} \\
\mathrm{RV} \\
\end{array}$ & $\begin{array}{r}7 \\
44 \\
\end{array}$ & $0.59(0.19-1.87)$ & 0.369 & 0.369 \\
\hline & RV+VV vs. RR & \begin{tabular}{|l|}
$\mathrm{RR}$ \\
$\mathrm{RV}+\mathrm{VV}$ \\
\end{tabular} & $\begin{array}{r}7 \\
36 \\
\end{array}$ & \begin{tabular}{|l|}
$\mathrm{RR}$ \\
$\mathrm{RV}+\mathrm{VV}$ \\
\end{tabular} & $\begin{array}{r}7 \\
93 \\
\end{array}$ & $0.39(0.13-1.18)$ & 0.123 & 0.148 \\
\hline & VV vs. RV+RR & $\begin{array}{l}\mathrm{RR}+\mathrm{RV} \\
\mathrm{VV}\end{array}$ & $\begin{array}{l}33 \\
10\end{array}$ & \begin{tabular}{|l}
$\mathrm{RR}+\mathrm{RV}$ \\
$\mathrm{VV}$
\end{tabular} & $\begin{array}{l}51 \\
49\end{array}$ & $0.32(0.14-0.71)$ & 0.004 & 0.008 \\
\hline & V vs. R & \begin{tabular}{|l|}
$\mathrm{R}(\%)$ \\
$\mathrm{V}(\%)$ \\
\end{tabular} & \begin{tabular}{|l|}
$40(46.5)$ \\
$46(53.5)$ \\
\end{tabular} & \begin{tabular}{|l|}
$\mathrm{R}(\%)$ \\
$\mathrm{V}(\%)$ \\
\end{tabular} & \begin{tabular}{|r|}
$58(29.0)$ \\
$142(71.0)$ \\
\end{tabular} & $0.47(0.28-0.79)$ & 0.004 & 0.008 \\
\hline \multirow[t]{6}{*}{ 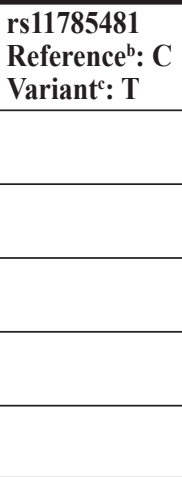 } & $\begin{array}{l}\text { risk per allele: } \\
0 ; 1 ; 2\end{array}$ & $\begin{array}{l}\text { RR (\%) } \\
\text { RV (\%) } \\
\text { VV (\%) }\end{array}$ & $\begin{array}{c}36(84.0) \\
7(16.0) \\
0(0.0)\end{array}$ & \begin{tabular}{|l|} 
RR (\%) \\
RV (\%) \\
VV (\%)
\end{tabular} & $\begin{array}{c}77(77.0) \\
23(23.0) \\
0(0.0)\end{array}$ & $0.65(0.26-1.66)$ & 0.365 & 0.395 \\
\hline & VV vs. RR & \begin{tabular}{|l|}
$\mathrm{RR}$ \\
$\mathrm{VV}$ \\
\end{tabular} & $\begin{array}{r}36 \\
0 \\
\end{array}$ & \begin{tabular}{|l|}
$\mathrm{RR}$ \\
$\mathrm{VV}$ \\
\end{tabular} & $\begin{array}{r}77 \\
0 \\
\end{array}$ & NA & NA & NA \\
\hline & RV vs. RR & $\begin{array}{l}\mathrm{RR} \\
\mathrm{RV} \\
\end{array}$ & $\begin{array}{r}36 \\
7\end{array}$ & $\begin{array}{l}\mathrm{RR} \\
\mathrm{RV} \\
\end{array}$ & $\begin{array}{l}77 \\
23\end{array}$ & $0.65(0.26-1.66)$ & 0.365 & 0.395 \\
\hline & RV+VV vs. RR & \begin{tabular}{|l|}
$R R$ \\
$R V+V V$ \\
\end{tabular} & $\begin{array}{r}36 \\
7 \\
\end{array}$ & \begin{tabular}{|l|}
$R R$ \\
$R V+V V$ \\
\end{tabular} & $\begin{array}{l}77 \\
23\end{array}$ & $0.65(0.26-1.66)$ & 0.365 & 0.395 \\
\hline & VV vs. RV+RR & $\begin{array}{l}\text { RR+RV } \\
\mathrm{VV}\end{array}$ & $\begin{array}{r}43 \\
0 \\
\end{array}$ & $\begin{array}{l}\mathrm{RR}+\mathrm{RV} \\
\mathrm{VV}\end{array}$ & $\begin{array}{r}100 \\
0\end{array}$ & NA & NA & NA \\
\hline & V vs. R & \begin{tabular}{|l|}
$\mathrm{R}(\%)$ \\
$\mathrm{V}(\%)$ \\
\end{tabular} & \begin{tabular}{|c|}
$79(92.0)$ \\
$7(8.0)$ \\
\end{tabular} & \begin{tabular}{|l|}
$\mathrm{R}(\%)$ \\
$\mathrm{V}(\%)$ \\
\end{tabular} & $\begin{array}{r}177(88.5) \\
23(11.5) \\
\end{array}$ & $0.68(0.28-1.66)$ & 0.395 & 0.395 \\
\hline \multirow[t]{6}{*}{$\begin{array}{l}\text { rs29362491 } \\
\text { Reference }^{\mathrm{b}} \text { : D } \\
\text { Variantc }: \text { I }\end{array}$} & $\begin{array}{l}\text { risk per allele: } \\
0 ; 1 ; 2\end{array}$ & $\begin{array}{l}\text { RR (\%) } \\
\text { RV (\%) } \\
\text { VV (\%) }\end{array}$ & \begin{tabular}{|r|}
$11(26.0)$ \\
$27(63.0)$ \\
$5(12.0)$
\end{tabular} & \begin{tabular}{|l|} 
RR (\%) \\
RV (\%) \\
VV (\%)
\end{tabular} & $\begin{array}{c}9(9.0) \\
61(61.0) \\
30(30.0)\end{array}$ & $0.37(0.19-0.70$ & 0.003 & 0.009 \\
\hline & VV vs. RR & $\begin{array}{l}\text { RR } \\
\text { VV }\end{array}$ & $\begin{array}{r}11 \\
5\end{array}$ & $\begin{array}{l}\text { RR } \\
\text { VV }\end{array}$ & $\begin{array}{l}9 \\
30\end{array}$ & $0.14(0.04-0.50)$ & 0.001 & 0.006 \\
\hline & RV vs. RR & \begin{tabular}{|l|}
$\mathrm{RR}$ \\
$\mathrm{RV}$ \\
\end{tabular} & \begin{tabular}{|l|}
11 \\
27 \\
\end{tabular} & \begin{tabular}{|l|}
$\mathrm{RR}$ \\
$\mathrm{RV}$ \\
\end{tabular} & $\begin{array}{r}9 \\
61 \\
\end{array}$ & $0.36(0.13-0.98)$ & 0.040 & 0.040 \\
\hline & $\mathrm{RV}+\mathrm{VV} v s . \mathrm{RR}$ & \begin{tabular}{|l|}
$R R$ \\
$R V+V V$ \\
\end{tabular} & $\begin{array}{l}11 \\
32 \\
\end{array}$ & \begin{tabular}{|l|} 
RR \\
RV+VV \\
\end{tabular} & $\begin{array}{r}9 \\
91 \\
\end{array}$ & $0.29(0.11-0.76)$ & 0.009 & 0.014 \\
\hline & VV vs. RV+RR & $\begin{array}{l}\text { RR+RV } \\
\mathrm{VV}\end{array}$ & $\begin{array}{r}38 \\
5\end{array}$ & \begin{tabular}{|l}
$\mathrm{RR}+\mathrm{RV}$ \\
$\mathrm{VV}$
\end{tabular} & $\begin{array}{l}70 \\
30\end{array}$ & $0.31(0.11-0.86)$ & 0.019 & 0.023 \\
\hline & V vs. R & \begin{tabular}{|l|}
$\mathrm{R}(\%)$ \\
$\mathrm{V}(\%)$
\end{tabular} & \begin{tabular}{|l|}
$49(57.0)$ \\
$37(43.0)$ \\
\end{tabular} & $\begin{array}{l}\mathrm{R}(\%) \\
\mathrm{V}(\%)\end{array}$ & $\begin{array}{r}79(39.5) \\
121(60.5)\end{array}$ & $0.49(0.30-0.82)$ & 0.006 & 0.012 \\
\hline
\end{tabular}

OR: odds ratio; 95\% CI: 95\% confidence interval; RR genotype: homozygosity for the wild-type allele; RV genotype: heterozygosity for the wild-type and non wild-type alleles; VV genotype: homozygosity for the non wild-type allele; NA: not assigned.

a The $p$ value was corrected for multiple comparisons.

${ }^{\mathrm{b}}$ The reference wild-type allele.

c The variant non wild-type allele. 
Statistical Package for the Social Sciences (SPSS) version 24.0 software (https://www.ibm.com/product/spssstatistics) and Project for Statistical Computing (R) (version 3.6.1) software (https://www.r-project.org/), to identify the differences in variant contributions between the two groups under the six models of genetic association. Haldane Anscombe correction ( 0.5 is added to all cells of the contingency table) was used when we had cells in the contingency table with zero counts. In addition, the false discovery rate (FDR) method was applied to correct for bias caused by multiple comparisons [14]. The odds ratio (OR) and 95\% confidence interval $(95 \% \mathrm{CI})$ was estimated, and a $p$ value of $<0.05$ was considered to be statistically significant.

\section{RESULTS}

The association of rs28362491, rs2277923, rs4531631 and rs11785481 polymorphisms are shown in Table 2. The genotype frequencies of the above variants in CHD patients and controls were in HWE. The polymorphism rs28362491 was associated with decreased risk of CHD with the additive [risk per allele RR genotype (homozygosity for the wild-type allele); RV genotype (heterozygosity for the wild-type and non wild-type alleles); VV genotype (homozygosity for non wild-type allele): $p=$ 0.003], homozygous (VV vs. RR: $p=0.001$ ), heterozygous (RV vs. RR: $p=0.040)$, dominant (RV+VV vs. RR: $p=0.009)$, recessive (VV vs. $\mathrm{RV}+\mathrm{RR}: p=0.019)$ and allelic model ( $\mathrm{V} v s . \mathrm{R}: p=0.006)$. Also, decreased risk was found with the additive (risk per allele RR, RV, VV: $p$ $=0.004)$, homozygous (VV vs. RR: $p=0.015$ ), recessive (VV vs. RV+RR: $p=0.004)$ and allelic model (V vs. R: $p=0.004)$ for polymorphism rs2277923. Additionally, when the FDR was applied, the association that remained significant concerned both of rs28362491 and rs2277923 variants, according to allelic model $(p=0.012$ and $p=$ 0.008 , respectively). There was no statistical difference of rs4531631 and rs11785481 polymorphism distribution between the two groups $(p>0.05)$.

\section{DISCUSSION}

To date, several studies have reported that genetic and epigenetic variations play a crucial role in CHD susceptibility, however, the pathogenesis of disease is highly complex and largely unknown. Mutations in genes controlling cardiac development and regulation, such as GATA4, NKX2-5, TBX5 [15], NOTCH1, TBX1, TBX20, CFC1, $C I T E D 2, C R E L D 1$, are associated with non syndromic $\mathrm{CHD}$ [1]. In this case-control study, we examined the association of variants in NFKB1, RANKL, GATA4 and NKX2-5 genes with risk of CHD in patients of Greek origin.
Up to the present, polymorphisms in $N F-\kappa B$ have been implicated in the pathogenesis of CHD. The NFKB1 (-94ins/ delATTG) polymorphism (rs28362491) has been broadly studied in cardiovascular diseases as a regulator of various biological processes, such as inflammation, proliferation and apoptosis. The NFKB1 gene encodes both p50 and p105 subunits of $N F-\kappa B$ protein. Deletion of one $A T T G$ repeat in the promoter region of $N F K B 1$ may result in lower levels of p50 homodimer by reduced p50 synthesis [16]. Partial depletion of p50 may decrease the antiinflammatory response because the formation of the pro inflammatory p65/p50 heterodimer depends on the concentration of $\mathrm{p} 50$. Consequently, it may be that individuals with carrying allele D are genetically determined toward a higher inflammatory response [17]. A previous study [17] recognized that D-allele carriers of NFKB1 (-94ins/ delATTG) are at increased risk of coronary heart disease, and may therefore show that inflammation is a potential mechanism for CHD development. Thus, it could reflect a positive association between human carrying allele D of rs28362491 and congenital cardiovascular anomalies.

In our study, we recognized a strong association between rs28362491 with the susceptibility to CHD. Individuals carrying allele D (ID/DD) of rs28362491, are at higher risk for CHD compared to those without allele D (II genotype) according to all six genetic models of analysis. In contrast to our results, positive association of the allele I with increased risk for development of an atrial septal defect (ASD), as well as with a ventricular septal defect (VSD), were demonstrated [1]. The discrepancy of results among diverse populations may be related to the racial and geographic differences.

In line with $N F K B 1$, the genetic variant $R A N K L$ (rs45311631) was also shown to be a significant variant in predisposition to CHD in a Chinese population [10]. The RANKL gene is a member of TNF family is a type II trans-membrane peptide. Furthermore, it is identified in numerous cell types, such as T and B cells, mammary ligands, vascular endothelial cells and synovial fibroblasts [18]. Decreased production of a $R A N K L$ significantly inhibited the NF- $\kappa B$ signaling pathway and thus, may affect CHD risk $[10,11]$. Consistent with these findings, RANKL may also modulate CHD risk [10]. In the present study, no association was detected between the variant rs45311631 of the RANKL gene and CHD in the patients of Greek origin.

There are connections between normal heart structure and multiple transcription factors, therefore, any mutation in transcription factor may lead to abnormal cardiac development and CHD. Transcription factor GATA4 contains a zinc finger domain that binds to specific DNA. The GATA4 gene is highly conserved during evolution and plays a critical role in cardiac stem cell differentiation and cardio- 
genesis [6]. In addition, mutations in the GATA4 gene can cause congenital cardiac anomalies and thus, deletions or duplications and point mutations of the gene, play a role in CHD susceptibility [8]. Mutations throughout the GATA4 gene have been associated with many types of abnormal heart structure such as VSDs, ASDs and pulmonary stenosis, and different alterations in the same gene can cause different CHD subgroups [6]. A previous study identified association between the $+1158 \mathrm{~T}$ allele in the 3'UTR of the GATA4 gene (rs11785481) with a reduced risk for CHD in a group of 146 Caucasian patients [8]. In our results, no positive association was found, either in genotype or allele frequencies of the GATA4 rs11785481 polymorphism, indicating low mutation frequency of GATA4 in the Greek population. A potential explanation for this discrepancy may be related to the restricted group of CHD patients and the geographic differences.

Furthermore, the GATA4 gene expression has a direct impact on the embryonic and postnatal development of heart and acts synergistically with other transcription factors, such as NKX2-5 during cardiogenesis [8,19]. Cardiac transcription factor NKX2-5 acts in combination with GATA4 in genetic, transcriptional and biochemical processes during formation of the heart [3]. The NKX2-5 gene mutations regulate heart morphogenesis and function and were detected in patients suffering from tetralogy of Fallot. Also, GATA4 alterations were shown to impair interactions with $N K X 2-5$, causing CHD [3]. NKX2-5 is an evolutionarily conserved homeobox protein gene and was first identified to be implicated in diverse manifestations of heart defects [5]. In the present study, our results showed that a significant statistical association exists between rs2277923 and CHD. Specially, the A allele of rs2277923 in the NKX2-5 gene was found to be protective in terms of CHD risk, as proved by the majority of models of the statistical analysis. Likewise, Shi et al. [20] indicated that individuals carrying the $\mathrm{G}$ allele of rs2277923 had increased risk of developing VSD than those with an A allele. In contrast to our association analysis, a previous study identified that the rs2277923 SNP on the NKX2-5 gene is linked to the sporadic ASDs in the Chinese Yunnan population and the A allele of rs2277923 is a potential risk factor resulting in ASDs [5]. Nevertheless, there are some different outcomes in CHD studies, which presented that rs2277923 has no role in sporadic CHD pathogenesis in Chinese patients $[21,22]$. The opposite research results may be related to the races and region differences.

In conclusion, our findings suggest the NFKB1 (rs28362491) and NKX2-5 (rs2277923) gene polymorphism as potential biomarkers of CHD in a Greek population. However, further studies in more CHD patients from different populations are needed to explore the as- sociation between rs28362491, rs2277923, rs4531631 and rs11785481 polymorphisms and CHD occurrence.

Declaration of Interest. The authors report no conflicts of interest. The authors alone are responsible for the content and writing of this article.

\section{REFERENCES}

1. Zhang D, Li L, Zhu Y, Zhao L, Wan L, Lv J, et al. The NFKB1 -94 ATTG insertion/deletion polymorphism (rs28362491) contributes to the susceptibility of congenital heart disease in a Chinese population. Gene. 2013; 516(2): 307-310.

2. Pan Y, Wang ZG, Liu XY, Zhao H, Zhou N, Zheng GF, et al. A novel TBX1 loss-of-function mutation associated with congenital heart disease. Pediatr Cardiol. 2015; 36(7): 1400-1410.

3. Tong YF. Mutations of NKX2.5 and GATA4 genes in the development of congenital heart disease. Gene. 2016; 588(1): 86-94.

4. Chaix MA, Andelfinger G, Khairy P. Genetic testing in congenital heart disease: A clinical approach. World J Cardiol. 2016; 8(2): 180-191.

5. Cao Y, Wang J, Wei C, Hou Z, Li Y, Zou H, et al. Genetic variations of NKX2-5 in sporadic atrial septal defect and ventricular septal defect in Chinese Yunnan population. Gene. 2016; 575(1): 29-33.

6. Su W, Zhu P, Wang R, Wu Q, Wang M, Zhang X, et al. Congenital heart diseases and their association with the variant distribution features on susceptibility genes. Clin Genet. 2017; 91(3): 349-354.

7. Wang Z, Zou L, Zhong R, Zhu B, Chen W, Shen N, et al. Associations between two genetic variants in NKX2-5 and risk of congenital heart disease in Chinese population: a meta-analysis. PLoS One. 2013; 8(8): e70979.

8. Pulignani S, Vecoli C, Sabina S, Foffa I, Ait-Ali L, Andreassi MG. 3'UTR SNPs and haplotypes in the GATA4 gene contribute to the genetic risk of congenital heart disease. Rev Esp Cardiol (Engl Ed). 2016; 69(8): 760-765.

9. Yang X, Li P, Tao J, Qin C, Cao Q, Gu J, et al. Association between NFKB1 -94ins/del ATTG promoter polymorphism and cancer susceptibility: An updated metaanalysis. Int J Genomics. 2014; 2014: 612972.

10. Wang F, Wang H, Wang L, Zhou S, Chang M, Zhou J, et al. Association between single nucleotide polymorphisms in NFATC1 signaling pathway genes and susceptibility to congenital heart disease in the Chinese population. Pediatr Cardiol. 2016; 37(8): 1548-1561. 
11. Yang J, Si D, Zhao Y, He C, Yang P. S-amlodipine improves endothelial dysfunction via the RANK/ RANKL/OPG system by regulating microRNA-155 in hypertension. Biomed Pharmacother. 2019; 114: 108799.

12. Chen B, Wu W, Sun W, Zhang Q, Yan F, Xiao Y. RANKL expression in periodontal disease: Where does RANKL come from? Biomed Res Int. 2014; 2014: 731039 .

13. Bishop KA, Wang X, Coy HM, Meyer MB, Gumperz JE, Pike JW. Transcriptional regulation of the human TNFSF11 gene in T cells via a cell type-selective set of distal enhancers. J Cell Biochem. 2015; 116(2): 320-330.

14. Sweeting MJ, Sutton AJ, Lambert PC. What to add to nothing? Use and avoidance of continuity corrections in meta-analysis of sparse data. Stat Med. 2004; 23(9): 1351-1375.

15. Cao Y, Lan W, Li Y, Wei C, Zou H, Jiang L. Single nucleotide polymorphism of NKX2-5 gene with sporadic congenital heart disease in Chinese Bai population. Int J Clin Exp Pathol. 2015; 8(11): 14917-1424.

16. Lai HM, Li XM, Yang YN, Ma YT, Xu R, Pan S, et al. Genetic variation in NFKB1 and NFKBIA and susceptibility to coronary artery disease in a Chinese Uygur population. PLoS One. 2015; 10(6): e0129144.
17. Vogel U, Jensen MK, Due KM, Rimm EB, Wallin $\mathrm{H}$, Nielsen MR, et al. The NFKB1 ATTG ins/del polymorphism and risk of coronary heart disease in three independent populations. Atherosclerosis. 2011; 219(1): 200-204.

18. Lo Iacono N, Pangrazio A, Abinun M, Bredius R, Zecca M, Blair HC, et al. RANKL cytokine: From pioneer of the osteoimmunology era to cure for a rare disease. Clin Dev Immunol. 2013; 2013: 412768.

19. Yang XY, Jing XY, Chen Z, Liu YL. Correlation between GATA4 gene polymorphism and congenital heart disease. Int J Clin Exp Med. 2015; 8(9): 1673316736.

20. Shi L, Shen AD, Li XF, Bai S, Guan XL, Li ZZ. Mutation screening of $\mathrm{Nkx} 2.5$ gene and association study in exon1 in Chinese with congenital heart disease. J Cap Univ Med Sci. 2005; 26(5): 525-528.

21. Yin J, Qian J, Dai G, Wang C, Qin Y, Xu T, et al. Search of somatic mutations of NKX2-5 and GATA4 genes in Chinese patients with sporadic congenital heart disease. Pediatr Cardiol. 2019; 40(1): 17-22.

22. Zheng J, Li F, Liu J, Xu Z, Zhang H, Fu Q, et al. Investigation of somatic NKX2-5 mutations in Chinese children with congenital heart disease. Int J Med Sci. 2015; 12(7): 538-543. 